\title{
The Relationship between Programme Context and Memory for Sexually Humorous Television Advertisements
}

\author{
A. Cheung1, Adrian Furnham ${ }^{2 *}$ \\ ${ }^{1}$ Research Department of Clinical, Educational and Health Psychology, University College London, London, UK \\ ${ }^{2}$ Norwegian Business School (BI), Olso, Norway \\ Email: *a.furnham@ucl.ac.uk
}

How to cite this paper: Cheung, A., \& Furnham, A. (2021). The Relationship between Programme Context and Memory for Sexually Humorous Television Advertisements. Psychology, 12, 255-268.

https://doi.org/10.4236/psych.2021.122016

Received: January 8, 2021

Accepted: February 22, 2021

Published: February 25, 2021

Copyright $\odot 2021$ by author(s) and Scientific Research Publishing Inc. This work is licensed under the Creative Commons Attribution International License (CC BY 4.0).

http://creativecommons.org/licenses/by/4.0/

\begin{abstract}
This study investigated the programme context effect on the memory for embedded TV advertisements. Participants watched a video consisted of either a non-humorous programme or a humorous programme, with six advertisements inserted into the mid break. Advertisements were either nonhumorous or humorous of which three of them contained sexual themes. Participants had to rate the programme, and were tested on brand recognition, free recall and cued recall. Humorous advertisements were better recalled within non-humorous programme while non-humorous advertisements were better recalled within humorous programme. Humorous advertisements with sexual content were recalled the least compared to those without this content. Implications and limitations were noted.
\end{abstract}

\section{Keywords}

Sex, Humour, Television, Advertising, Recognition, Recall

\section{Introduction}

Does sex, violence or humour sell? (Lull \& Bushman, 2015). That is, are advertisements with sexual or humorous imagery and themes more impactful in the sense that they are better remembered and lead to more sales? Does this depend as much on the programme within which the ads occur, and, if so, should the context be similar or different? This study is about this important area of research. The literature on the use of sexual imagery and humour in advertising has been kept apart whereas in effect many ads combine the two. We attempt to move this literature forward by looking at advertisements which combine both. 
We use classic experimental methodology and actual television ads to test our hypotheses.

This study looks at memory for sexually humorous and non-humorous advertisements in a humorous and non-humorous television programme. There continues to be a great deal of interest in effects of using humour (Chan \& Low, 2020; Hendriks \& Sttick, 2020; Shin \& Larson, 2002) and sex (Lawrence et al., 2021; Wirtz et al., 2018) in advertising. Whilst research has attempted to focus on either sex or violence where in reality these are often mixed. We believe we are the first to examine humorous and non-humorous ads all with a sexual content

Television programmes induce emotional states (arousal, excitement) which can shape memory for the programme and the embedded advertisements. However, the specific factors associated with this effect are still unclear (Furnham, 2019). Similarly, some programmes are more involving than others. Programme involvement is defined as an active, motivated state signifying interest and arousal induced by a television programme (Moorman, Neijens, \& Smit, 2007). Numerous studies on programme context effect, established a relationship between the programme involvement and advertisement recall, however the findings have been inconsistent. Lloyd and Clancy (1991) reviewed over 70 studies and found inconsistent results were partially due to the variation in the methodologies used in different studies. The studies that were conducted in the natural, real-world environment with more representative participants often resulted in studies that support the positive relationship

Kwon et al. (2019) recent meta-analytic review supports previous findings of programme context effects as greater programme liking positively affected advertisement memory, whereas highly arousing, humorous, violent, sexual, and suspenseful programme content reduced advertisement memory. However, the correlations between programme context and advertising memory were found to be weak suggesting that programme context does not have a large effect on advertisement effectiveness.

Another important factor is the congruity between programme and advertisement content. According to the cognitive priming theory, an advertisement will be more effective if it is presented in a programme of similar nature (Sanbonmatsu \& Fazio, 1991). The priming of verbal and visual materials takes place as a consequence of semantic relations existing between the prime and target. Likewise, construct accessibility theory highlights that semantic memory can be represented by several networks consisting of nodes that represent constructs. Associative pathways connect all these constructs, and each network represents connections that are grouped by stimuli such as similarity, congruity and semantic relatedness (Bryant \& Oliver, 2009). When a node is activated through memory retrieval, it leads to the immediate activation of all interrelated constructs along connections between networks; this process is referred as priming.

The consistency effects model describes people who are in a positive or negative mood are more altruistic compared to those who are in a neutral mood. 
Applying this to advertising effectiveness, audiences who watch "negative programmes" do not necessarily react negatively to advertisements with a matching negative mood, but process them as more effective as a social, empathic response (Cialdini \& Fultz, 1990; Stout \& Leckenby, 1986). The consistency in the mood for both the programme and televisions advertisements allows more positive reaction with regard to the latter component, even when an individual is in a relatively negative mood. Kamins, Marks and Skinner (1991) found significant results to support this explanation. The sad programme and happy advertisement combination resulted in a lower advertising evaluation.

The expectation of receiving congruent information is also thought to aid memory, allowing a more rapid recall and a longer retention time for information compared to incongruent stimuli. People are more likely to reject new or incongruent information which does not exist in the expected acceptance (Furnham, 2019).

Murphy, Cunningham and Wilcox (1979) conducted an experiment to test the memory performance for humorous and non-humorous advertisements separately in three different programme contextual environments-situation comedy, action/adventure and documentary. With the measurements of free recall, the results revealed that humorous advertisements were recalled better in a documentary, whereas non-humorous advertisements were recalled better in a situation comedy, reinforced by an apparent mood-contrast effect between them.

\section{Humorous advertisements}

Humour is widely used in advertising, with approximately 15 to 40 percent of television advertisements consist of humorous materials to some extent (Gulas \& Weinberger, 2006). It has attracted research interest for over forty years (Murphy et al., 1979; Sternthal \& Craig 1973; Speck, 1987; Warren et al., 2019).

There are contradictory findings in this area. Osterhouse and Brock (1970) found that humorous advertisements have more persuasive power as they distract audiences. This in turn leads to decreased levels of counter argumentation and therefore to an increase in message comprehension. On the contrary, Duncan and Nelson (1985) suggested that humorous content may increase audiences' attention but not their comprehension or persuasion. Their findings showed that the high level of attention inhibits the advertising message.

Weinberger and Gulas (1992) offer three possible reasons for contradictory findings. Firstly, there has not been a consistent empirical definition of comprehension among the studies some used a single recall measure whilst other used multiple measures. Secondly, different types of humorous advertisements were used including, comic wit, satire, full comedy, and sentimental humour, which would all have different effects on comprehension. Indeed, there are different types of humour, such as, self-enhancing, self-defeating, affiliative, sexual and aggressive (Martin et al., 2003). Thirdly, the variation in the types of products used in advertisements, whether if they were actual or fictional products might have contributed in the contradicting evidence.

Chung and Zhao (2003) found significant positive relationships between hu- 
morous advertisements and audiences' memory recall and attitudes. Goldberg and Gorn (1987) established that emotional advertisements lead to more positive reactions compared to informational advertisements. There was a significant programme by advertisements interaction, particularly emotional advertisements were found to induce a happier mood and influenced more by the programme context effect. Emotional advertisements such as those containing humour content are more likely to be remembered and associated with positive attitudes (Chung \& Zhao, 2003).

There have been various reviews of the effect of humor in advertising (Eisend, 2009, 2011, 2018). Eisend (2011) in a meta analysis concluded: "Humor reduces negative cognitions related to the ad because it serves as a distraction from counterargumentation. In order to maintain positive affect, humor reduces cognitive efforts, in particular those related to brand related cognitions, thus supporting a vampire effect; that is, humor distracts from processing central benefits of the brand. Humor exerts its strongest impact along affective paths, supporting the dominance of affective mechanisms. Affect and cognition do interplay in line with a congruency effect where the impact of positive affect on attitudes towards the ad is mediated by positive cognitions" (p. 115).

Han et al. (2017) study investigated the effects of programme context on memory for humorous television advertisements. They found when the programme ratings of humour, enjoyment and involvement were higher, unaided recall was poorer. In addition, unaided recall of the advertisements was better when they were embedded within a non-humorous programme. However, there was no significant programme-advertisement interaction effect. Overall, both free and cued recall were higher for humorous advertisements than for the non-humorous advertisements.

What if an ad uses both humour and sex to attract viewer attention? The popular use of such sexual content seems to reflect the advertisers' belief that "sex sells", through attracting attention, appealing to audiences that approve of its use, and illustrating the "outcomes" of using the products. There have been a number of studies that examined the effect of sexual advertisements and programmes, but which came to different conclusions that both "sex sells" or "does not sell” (King et al., 2015; Lawrence et al., 2021; Leka et al., 2013; Parker \& Furnham, 2007; Wong et al., 2019).

Bushman (2005) noted that though individuals tend to pay more attention to sexual content than non-sexual content, the processing of sexual content demands a greater cognitive capacity and consequently limits the available cognitive resources to process other stimuli. In particular, for advertising effectiveness, audiences may pay attention to sexual advertisements, but not necessarily on the advertising message and may even be distracted by the sexual content.

Lull and Bushman (2015) in a meta-analysis on the effects of sexual/ violent media and sexual/ violent advertisements on brand memory, brand attitudes and purchasing intention found that participants evaluated the brands as less favourable when they were advertised in sexual advertisements compared to in 
nonsexual advertisements. The explanation of audiences' negative attitudes towards sexual content is that it is regarded as promoting rape and sex, therefore, contributing to this finding (Zillmann, 2000).

The current study aims to investigate the programme context effect on memory for sexually humorous advertisements. It partly attempted to replicate previous findings with new materials but distinguish the difference between memory for humorous advertisements where the humour was or not based on sexual innuendo. We predicted that:

H1: (a) Humorous advertisements will be better recalled within non-humorous programme; (b) Non-humorous advertisements will be better recalled within humorous programme.

H2: Humorous advertisements with sexual content will be less recalled compared to those without this content.

\section{Method}

\subsection{Participants}

In all 69 participants took part in this study including 23 males and 46 females, aged $18-28(\mathrm{M}=22.34 \mathrm{yrs}, \mathrm{SD}=3.14)$. They were volunteers who agreed to take part in a television study. Many were students at various institutions. They were randomly assigned to one of the four conditions: Group 1-Non-humorous programme \& Non-humorous advertisement $(n=20)$; Group 2-Non-humorous programme \& Humorous advertisement $(n=16)$; Group 3-Humorous programme \& Non-humorous advertisement $(n=20)$; Group 4-Humorous programme \& Humorous advertisement $(n=13)$. An a priori power analysis was conducted using $G^{\star}$ Power (Faul, Erdfelder, Lang, \& Buchner, 2007) indicated that to detect a standardised effect size of $f=.25$ (moderate), with a $5 \%$ significance level and 95\% power, the minimum sample size required was 43 individuals. We thus had more than was required in this study.

\subsection{Materials}

\section{Programmes}

The non-humorous programme was chosen from the "Australian Broadcasting Corporation News" which was 17 minutes and 24 seconds long. The humorous programme was an episode from the comedy show "Mr Bean" which was 23 minutes and 3 seconds long.

\section{Advertisements}

In the pilot study, 24 advertisements of the same product type were reduced to 12 advertisements using the advertisement subjective rating scales from Furnham, Gunter and Walsh (1998)'s pilot study. Participants had to rate the advertisements by responding to a counter-balanced set of five 7-point scales, which included these adjectives: humorous, amusing, clever, funny and boring. The 6 advertisements which were rated to be the most humorous with three of them containing sexual content and the 6 which rated to be the least humorous were 
selected for use in the study.

The final 12 advertisements were all about soda drinks which were inserted in the mid-break of the programmes. The advertising break occurred at 11 minutes and 1 second since the beginning of the news and at 11 minutes and 10 seconds since the beginning of the comedy show. Attempts were made to choose more obscure and less recent advertisements to avoid participants already having prior memory on certain products. The non-humorous advertisements included these brands: 7 UP, Cresta, Crush, Fresca, Squirt and Tango (Total length: 3 minutes and 4 seconds). The humorous advertisements included these brands: Corba, Zest, Dr Pepper, Burn, Sun Drop and Tab (Total length: 3 minutes and 54 seconds).

All of the content of programmes and advertisements were found and downloaded from "Youtube". The video clips used in the experiment were edited using "Windows Movie Maker", where the 6 advertisements were edited into the mid-break of the programme in each condition.

\section{Questionnaires}

The first set was on programme ratings. Participants had to rate 17 bipolar adjectival measures about the programme (Parker \& Furnham, 2007). Second, free recall: participants were required to write as much as they could remember about the advertisements showed in the mid-break of the programme, such as the brand name, background and advertisement content. The third part concerned brand name recognition, 36 random brand names were provided, and participants were asked to identify the six that were shown in the advertisements. The fourth set was on cued recall, the brand name was given and participants were provided with four questions for each of the six advertisement in a multiple-choice format. These questions were on the more detailed information of the advertisement content, such as the slogan, the colour of the actor's shirt and the benefits emphasised for the advertised product.

Free recall descriptive answers were marked out of 32 regarding to a list of salient points produced for each set of the advertisements. These descriptions comprised almost all the detailed information in the participants' memory recall answers. For the brand name recognition test, 1 score was given for each of the correctly identified brand name. For the cued recall test, 1 score was given for each of the correct multiple choice answer. The free and cued recall test scores were combined to produce an overall recall score.

All questions were the same as those used in previous studies in the area (King et al., 2015; Lawrence et al., 2021).

\subsection{Procedure}

Ethical permission was sought and received. The experiment was run online by Qualtrics, using a university subject panel. Participants were shown the information sheet and had to agree on giving their consent for taking part in this experiment which was followed by filling in their demographic details. They were told that the aim of the study was on programme evaluation, and there were two 
parts in the study which would last approximately 30 minutes in total: In the first part, they would be provided with a 20 minutes video. In the second part, they would be required to answer a few questionnaires. There was no mention of the advertisements at all. A time was set on qualtrics to ensure a button to proceed to the next stage would only appear after the duration of the video was over. At the end of the study, there was debriefing to explain the actual aim of the study.

\section{Results}

\section{1) Programme ratings factor}

The programme evaluation data was examined by a factor analysis with VARIMAX rotation to investigate the dimensional structure of participants' programme ratings. One factor was named humorous (48.69\% of variance) which was defined by 10 items: fun, humorous, happy, cheerful, funny, amusing, entertaining, enjoyable, relaxing and exciting. The other factor was named involving (30.23\% of variance) which was defined by 6 items: thought-provoking, involved, interesting, informative, absorbing and stimulating.

2) Programme ratings differences

Single-factor scores were produced by aggregating the ratings scales data on each factor. It was found that the difference between the two types of programmes was significant for the humorous factor $F(1,68)=8.37, p=.005$. The humorous programme was rated with a higher score $(M=4.24, S D=1.53)$ than the non-humorous programme $(\mathrm{M}=3.22, \mathrm{SD}=1.28)$. For the involving factor, the non-humorous programme was rated with a higher score $(\mathrm{M}=3.91, \mathrm{SD}=1.45)$ than the humorous programme $(\mathrm{M}=3.43$. $\mathrm{SD}=1.46)$, however, this difference was not significantly different, $F(1.68)=1.87, p=.17$.

3) Programme ratings and memory for advertisements

Partial correlations (controlling for gender) were conducted between the programme evaluation scores and brand recognition scores, cued recall scores, free recall scores and global recall scores (cued and recall test scores combined). Outliers for memory scores were checked and removed before conducting this analysis. It was found that all the correlations between the humorous factor/ involving factor and memory tests were positive. However, these correlations were not significant apart from the one for brand recognition and the involving factor, $r(66)=.25, p=.03$. Table 1 shows the partial correlation scores.

\section{4) Programme environment and memory for advertisements}

Two-way ANCOVAs (controlling for gender) were conducted to compare brand recognition, cued recall, free recall and global recall scores for advertisements as a function of both type of programme and type of advertisement (humorous and non-humorous). Outliers for memory scores were checked and removed before conducting this analysis. The mean memory scores are presented in Table 2 and Figure 1 and Figure 2.

It was found all memory scores were higher for non-humorous advertisements 


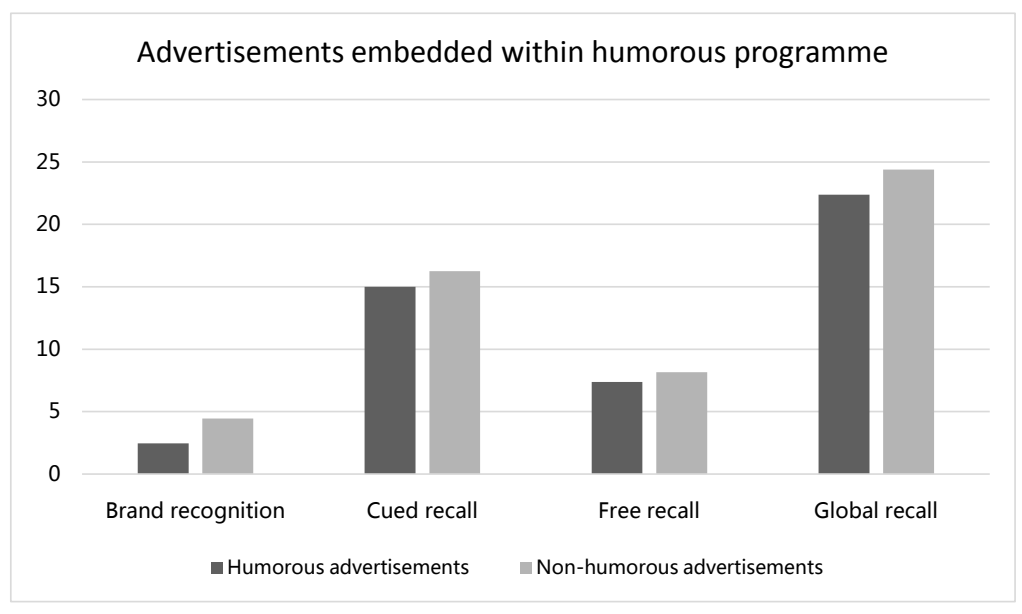

Figure 1. Mean memory scores for advertisements embedded within humorous programme.

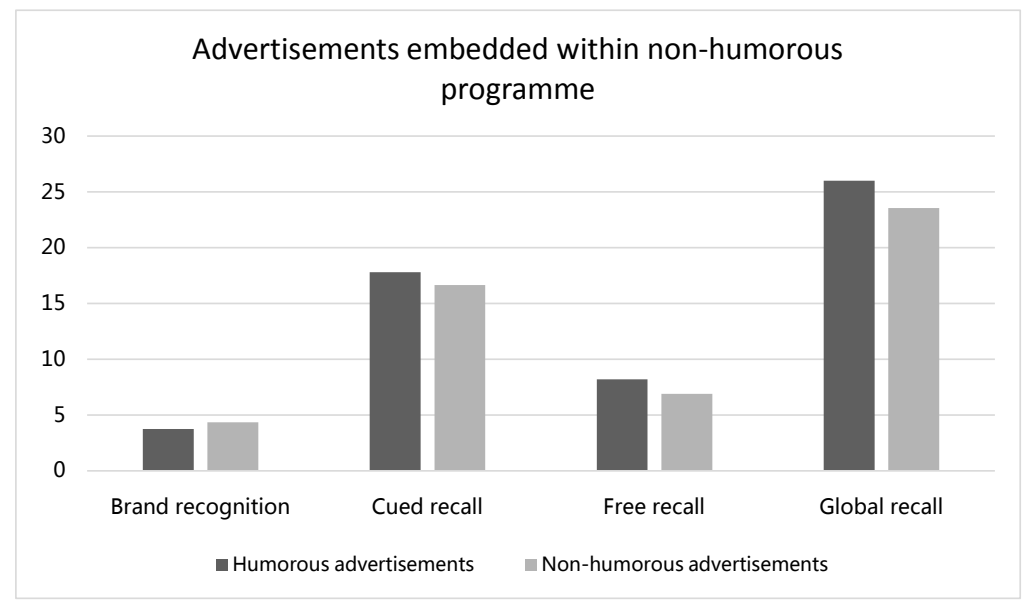

Figure 2. Mean memory scores for advertisements embedded within nonhumorous programme.

Table 1. Partial correlation scores between subjective rating factors and memory scores.

\begin{tabular}{cccc}
\hline & Humorous & Involving \\
\hline Brand recognition & .14 & .25 \\
Cued Recall & .07 & .09 \\
Free Recall & .18 & .12 \\
Global Recall & .16 & .13 \\
\hline
\end{tabular}

Table 2. Memory scores for both programme and advertisement type with 2 way ANCOVA.

\begin{tabular}{|c|c|c|c|c|c|c|c|}
\hline \multirow{2}{*}{$F(1,68)$} & \multicolumn{2}{|c|}{ Humorous Programme } & \multicolumn{2}{|c|}{ Non-humorous Programme } & \multirow{2}{*}{$\begin{array}{l}\text { Progr } \\
\text { effect }\end{array}$} & \multirow{2}{*}{$\begin{array}{c}\text { Ad } \\
\text { effect }\end{array}$} & \multirow{2}{*}{$\begin{array}{l}\text { Progr x Adv } \\
\text { interaction }\end{array}$} \\
\hline & Humorous Ad & Non-humorous Ad & Humorous Ad & Non-Humorous Ad & & & \\
\hline Brand recognition & 2.46 & 4.45 & 3.75 & 4.35 & 2.49 & $11.6^{* * *}$ & $3.47^{\star}$ \\
\hline Cued Recall & 15.00 & 16.25 & 17.81 & 16.65 & $4.59^{\star *}$ & .08 & $3.29^{*}$ \\
\hline Free Recall & 7.38 & 8.15 & 8.19 & 6.90 & .03 & .02 & 1.10 \\
\hline Global Recall & 22.38 & 24.40 & 26.00 & 23.55 & .92 & .00 & .26 \\
\hline
\end{tabular}


than humorous advertisements when they were embedded in a humorous programme. On the other hand, memory scores were higher for humorous advertisements than non-humorous advertisements when they were embedded in a non-humorous programme apart from the brand recognition score.

There was a significant advertisement type effect on brand recognition, $F(1$, 68) $=11.6, p=.001$, brands in non-humorous advertisements were better remember in both humorous and non-humorous programmes. There was also a significant programme type effect on cued recall, $p=.036$, advertisements were better remembered in non-humorous programme when measured with cued recall. The first pair of hypotheses were not supported but the general trends were present as humorous advertisements were better recalled within non-humorous programme, and non-humorous advertisements were recalled within humorous programme.

5) Memory for sexual humorous advertisements and non-sexual humorous advertisements

Paired samples t-tests were conducted to compare the brand name recognition, cued recall and free recall scores between non-sexual humorous advertisements and sexual humorous advertisements, in order to investigate if sexual content aided memory. For brand name recognition, non-sexual humorous advertisements $(\mathrm{M}=2.17, \mathrm{SD}=1.04)$ had a higher score than sexual humorous advertisements $(M=1.00, S D=.89)$, the difference was significant $t(28)=6.09$, $p<.001$. For cued recall test, non-sexual humorous advertisements $(\mathrm{M}=11.31$, $\mathrm{SD}=2.77)$ also had a higher score than sexual humorous advertisements $(\mathrm{M}=$ $5.24, \mathrm{SD}=1.50)$, the difference was significant $t(28)=10.61, p<.001$. For free recall test, non-sexual humorous advertisements $(\mathrm{M}=5.34, \mathrm{SD}=2.89)$ had a higher score than sexual humorous advertisements $(\mathrm{M}=2.48, \mathrm{SD}=1.57)$ with a significant difference, $t(28)=7.80, p<.001$. Hypothesis 2 was supported as humorous advertisements with sexual content were recalled the least compared to the humorous advertisements without this content.

\section{Discussion}

Positive correlations were found between the humorous and involving ratings factors for all memory tests (brand recognition, cued recall, free recall and global recall). However, the only significant correlation was for the involving factor and brand recognition. This was consistent with Srull's (1983) findings which showed a positive relationship between participants' mood states and their reactions to the advertisements. The more humorous and involving the programme was, the more likely participants would be in a positive mood. This would in turn trigger emotional processing which enabled the advertising messages to be recalled better. Norris et al. (2003) findings agreed with the current positive correlations but they achieved significant results which might be due to their attempt in creating a natural setting where participants could choose freely if they wanted to engage in the advertisements. In this current study, participants were 
forced to watch the embedded advertisements.

Kahneman (1973) suggested that high involving programmes may lead to continuous enhanced attention for advertisements which in turn resulted in the better recall. This was further verified by the transfer hypothesis stating that attention may be transferred from the previous content to the accompanying content. Various studies supported this (Lloyd \& Clancy, 1991; Moorman et al., 2012). One possible explanation for all the non-significant results would be that programme ratings evaluations would not significantly influence audiences' memory on advertisements because of 'selective exposure' (Norris et al., 2003), the most influential factor to interfere memory recall would depend on one's willingness to be engaged in such environment to perceive the advertising message.

Programme environment and memory for advertisements

The current study found that memory recall for non-humorous advertisements was better when they were embedded within humorous programme. Similarly, memory recall for humorous advertisements was better when they were embedded within non-humorous programme, apart from brand recognition which produced an opposite result. The first pair of hypotheses were not significant but the trends were present.

The general trends supported the beneficial effects of programme advertisement mood incongruity. It has been argued that incongruity would trigger tension and allow a more deliberate processing (LaTour \& Tanner, 2003). The current findings confirmed Murphy, Cunningham and Wilcox (1979)'s findings, humorous advertisements were recalled better within a less humorous contextual environment, whereas non-humorous advertisements would be recalled better within a more humorous contextual environment. This reinforced the mood contrast effect in which the difference between the mood induced by the programme and the advertisement will enhance memory for advertising message.

A significant advertisement type effect emerged for brand recognition; this was the only significant advertisement type effect across all measures of memory recall (cued recall, free recall and global recall). It was found that brand recognition scores for non-humorous advertisements were higher in both humorous and non-humorous programmes. Interestingly, the brand name recognition score in the non-humorous programme condition was the only result which opposed the general trend-mood contrast effect of the current findings. A possible explanation can be the significant positive partial correlation between the involving factor and brand recognition scores. The humorous and non-humorous programmes did not differ based on this involving factor, therefore both programmes were viewed as involving as each other. This in turn validated the positive relationship between programme induced involvement and memory recall (Kahneman, 1973; Krugman, Cameron \& White, 1995; Moorman et al., 2012).

In addition, a significant programme type effect emerged for cued recall, both humorous and non-humorous advertisements were better recalled within nonhumorous programme. Furnham, Gunter and Walsh (1998) found significant 
programme type effects across all measures for memory apart from cued recall. This difference might arise from the difference in number of questions provided in a multiple-choice format in cued recall tests. A serious programme environment may provide a generally more favourable surrounding for advertising. A less involving programme such as one with serious content, demands less cognitive resources, this in turn enhances the available cognitive resources to process advertisements (Kennedy, 1971).

This study added to the literature by distinguishing between sexual and non-sexual humorous ads. As predicted and in accordance with the general literature on sex in advertising the non-sexual humorous ads were recalled better than the humorous ads. Given the limited number of ads this finding merits replication. However, the results do point to the fact that different types of humorous ads, based on different types of humour may have very different effects on recall.

\section{Practical Implications}

All those involved in the advertising and marketing world are interested in producing advertisements that work in the sense that they get noticed, remembered and in the long run, lead to greater sales of the product. One question for them is introducing either or both sexual imagery and innuendo as well as humour. Whilst we know these can be very effective at attracting attention, they can also offend people. However just as important is the context of the advertisement: that is the surrounding programme and whether it should in some sense be similar to (congruent) or different from (incongruent) the advertisement. In this study we found as others have before "sex does not sell" (Bushman, 2005). We also found some evidence for the effectiveness of programme incongruity. It is certainly true that the results of studies are very equivocal (King et al., 2015; Leka et al., 2013) and much clearly depends on the amount and type of imagery. Certainly the advice for advertisers is that there is more evidence that humour "works better" than sex but that both are highly nuanced in the eyes of consumers.

\section{Limitations}

Like all studies this had limitations. We had a restricted number of advertisements and programmes. To do experimental work of this kind is always problematic because the stimulus materials are not designed and made according to careful criteria: they have to be found and matched as much as possible. It was in this quest that we recognised that sex and humour in advertisements were often confounded. One obvious explanation for findings not replicating in this area is the stimulus materials which can often be dramatic can have a very powerful impact as King et al. (2015) showed.

It would have been desirable to explore the effects of different types of humour. Similarly, we chose to control for sex differences rather than explore them in detail though differences seem more apparent when the products are clearly related to one or other gender. We did not counterbalance advertisements across 
participants to control order effects though it has not proved significant in studies which did it. Also, would also have been interesting to explore the buying intentions of the participants with respect to each of the advertised product.

Finally, there is always the question of the generalisability of the findings given the unrepresentative sample of mainly well-educated young people in Great Britain. The question is whether less well-educated people from a more conservative culture react differently to sexual imagery and humour in TV advertising? This is an empirical question worthy of more research, though reviews in this area would suggest that many of these findings would, for theoretical reasons, generalise across culture (Eisend, 2018).

\section{Conflicts of Interest}

The authors declare no conflicts of interest regarding the publication of this paper.

\section{References}

Bryant, J., \& Oliver, M. B. (Eds.) (2009). Media Effects: Advances in Theory and Research. New York: Routledge. https://doi.org/10.4324/9780203877111

Bushman, B. J. (2005). Violence and Sex in Television Programs Do Not Sell Products in Advertisements. Psychological Science, 16, 702-708. https://doi.org/10.1111/j.1467-9280.2005.01599.x

Chan, F. F. Y., \& Lowe, B. (2020). Placing Products in Humorous Scenes: Its Impact on Brand Perception. European Journal of Marketing. https://doi.org/10.1108/EJM-10-2018-0701

Chung, H., \& Zhao, X. (2003). Humour Effect on Memory and Attitude: Moderating Role of Product Involvement. International Journal of Advertising, 22, 117-144. https://doi.org/10.1080/02650487.2003.11072842

Cialdini, R. B., \& Fultz, J. (1990). Interpreting the Negative Mood-Helping Literature via "Mega"-Analysis: A Contrary View. Psychological Bulletin, 107, 210-214. https://doi.org/10.1037/0033-2909.107.2.210

Duncan, C. P., \& Nelson, J. E. (1985). Effects of Humor in a Radio Advertising Experiment. Journal of Advertising, 14, 33-64. https://doi.org/10.1080/00913367.1985.10672944

Eisend, M. (2009). A Meta-Analysis of Humor in Advertising. Journal of the Academy of Marketing Science, 37, 191-203. https://doi.org/10.1007/s11747-008-0096-y

Eisend, M. (2011). How Humor in Advertising Works: A Meta-Analytic Test of Alternative Models. Marketing Letters, 22, 115-132. https://doi.org/10.1007/s11002-010-9116-Z

Eisend, M. (2018). Explaining the Use and Effects of Humour in Advertising: An Evolutionary Perspective. International Journal of Advertising, 37, 526-547. https://doi.org/10.1080/02650487.2017.1335074

Faul, F., Erdfelder, E., Lang, A.-G., \& Buchner, A. (2007). G*Power 3: A Flexible Statistical Power Analysis Program for the Social, Behavioral, and Biomedical Sciences. Behaviour Research Methods, 39, 175-191. https://doi.org/10.3758/BF03193146

Furnham, A. (2019). Advertising: The Contribution of Applied Cognitive Psychology. Applied Cognitive Psychology, 33, 168-175. https://doi.org/10.1002/acp.3458

Furnham, A., Gunter, B., \& Walsh, D. (1998). Effects of Programme Context on Memory of Humorous Television Commercials. Applied Cognitive Psychology, 12, 555-567. 
https://doi.org/10.1002/(SICI)1099-0720(1998120)12:6<555::AID-ACP537>3.0.CO;2-X

Goldberg, M. E., \& Gorn, G. J. (1987). Happy and Sad TV Programs: How They Affect Reactions to Commercials. Journal of Consumer Research, 14, 387-403. https://doi.org/10.1086/209122

Gulas, C. S., \& Weinberger, M. G. (2006). Humor in Advertising: A Comprehensive Analysis. Armonk, NY: ME Sharpe.

Han, D., McClelland, A., \& Furnham, A. (2017). The Effects of Programme Context on Memory for Humorous Television Commercials. Applied Cognitive Psychology, 31, 586592. https://doi.org/10.1002/acp.3354

Hendriks, H., \& Strick, M. (2020). A Laughing Matter? How Humor in Alcohol Ads Influences. Interpersonal Communication and Persuasion, Health Communication, 35, 1821-1829. https://doi.org/10.1080/10410236.2019.1663587

Kahneman, D. (1973). Attention and Effort (p. 246). Englewood Cliffs, NJ: Prentice-Hall.

Kamins, M. A., Marks, L. J., \& Skinner, D. (1991). Television Commercial Evaluation in the Context of Program Induced Mood: Congruency versus Consistency Effects. Journal of Advertising, 20, 1-14. https://doi.org/10.1080/00913367.1991.10673209

Kennedy, J. R. (1971). How Program Environment Affects TV Commercials. Journal of Advertising Research, 11, 33-39.

King, J., McClelland, A., \& Furnham, A. (2015). Sex Really Does Sell: The Recall of Sexual and Non-Sexual Television Advertisements in Sexual and Non-Sexual Programmes. Applied Cognitive Psychology, 29, 210-216. https://doi.org/10.1002/acp.3095

Krugman, D. M., Cameron, G. T., \& White, C. M. (1995). Visual Attention to Programming and Commercials: The Use of In-Home Observations. Journal of Advertising, 24, 1-12. https://doi.org/10.1080/00913367.1995.10673464

Kwon, E., King, K., Nyilasy, G., \& Reid, L. (2019). Impact of Media Context on Advertising Memory: A Meta-Analysis of Advertising Effectiveness. Journal of Advertising Research, 59, 99-128. https://doi.org/10.2501/JAR-2018-016

LaTour, M. S., \& Tanner, J. F. (2003). Radon: Appealing to Our Fears. Psychology and Marketing, 20, 377-394. https://doi.org/10.1002/mar.10078

Lawrence, H., Furnham, A., \& McClelland, A. (2021). Sex Does Not Sell: The Effect of Sexual Advertising on Advertisement and Brand Recall across Implicit and Explicit Memory Measures. Perceptual and Motor Skills. https://doi.org/10.1177/0031512521990352

Leka, J., McClelland, A., \& Furnham, A. (2013). Memory for Sexual and Nonsexual Television Commercials as a Function of Viewing Context and Viewer Gender. Applied Cognitive Psychology, 27, 584-592. https://doi.org/10.1002/acp.2939

Lloyd, D. W., \& Clancy, K. J. (1991). Television Program Involvement and Advertising Response: Some Unsettling Implications for Copy Research. Journal of Consumer Marketing, 8, 61-74. https://doi.org/10.1108/07363769110035162

Lull, R., \& Bushman, B. (2015). Does Sex and Violence Sell? Psychological Bulletin, 141, 1022-1048. https://doi.org/10.1037/bul0000018

Martin, R. A., Puhlik-Doris, P., Larsen, G., Gray, J., \& Weir, K. (2003). Individual Differences in Uses of Humor and Their Relation to Psychological Well-Being: Development of the Humor Styles Questionnaire. Journal of Research in Personality, 37, 48-75. https://doi.org/10.1016/S0092-6566(02)00534-2

Moorman, M., Neijens, P. C., \& Smit, E. G. (2007). The Effects of Program Involvement on Commercial Exposure and Recall in a Naturalistic Setting. Journal of Advertising, 36, 121-137. https://doi.org/10.2753/JOA0091-3367360109 
Moorman, M., Willemsen, L. M., Neijens, P. C., \& Smit, E. G. (2012). Program-Involvement Effects on Commercial Attention and Recall of Successive and Embedded Advertising. Journal of Advertising, 41, 25-38. https://doi.org/10.2753/JOA0091-3367410202

Murphy, J. H., Cunningham, I. C., \& Wilcox, G. B. (1979). The Impact of Program Environment on Recall of Humorous Television Commercials. Journal of Advertising, 8, $17-$ 21. https://doi.org/10.1080/00913367.1979.10717971

Norris, C. E., Colman, A. M., \& Aleixo, P. A. (2003). Selective Exposure to Television Programmes and Advertising Effectiveness. Applied Cognitive Psychology, 17, $593-$ 606. https://doi.org/10.1002/acp.892

Osterhouse, R. A., \& Brock, T. C. (1970). Distraction Increases Yielding to Propaganda by Inhibiting Counterarguing. Journal of Personality and Social Psychology, 15, 344-358. https://doi.org/10.1037/h0029598

Parker, E., \& Furnham, A. (2007). Does Sex Sell? The Effect of Sexual Programme Content on the Recall of Sexual and Non-Sexual Advertisements. Applied Cognitive Psychology, 21, 1217-1228. https://doi.org/10.1002/acp.1325

Sanbonmatsu, D. M., \& Fazio, R. H. (1991). Construct Accessibility: Determinants, Consequences, and Implications for the Media. In J. Bryant, \& D. Zillmann (Eds.), Communication. Responding to the Screen: Reception and Reaction Processes (pp. 45-62) Hillsdale, NJ: Lawrence Erlbaum Associates, Inc.

Shin, H., \& Larson, L. R. L. (2020). The Bright and Dark Sides of Humorous Response to Online Customer Complaint. European Journal of Marketing, 54, 2013-2047. https://doi.org/10.1108/EJM-08-2018-0522

Speck, P. S. (1987). On Humor and Humor in Advertising. Doctoral Dissertation, Lubbock, TX: Texas Tech University.

Srull, T. K. (1983). Affect and Memory: The Impact of Affective Reactions in Advertising on the Representation of Product Information in Memory. In R. P. Bagozzi, \& A. M. Tybout (Eds.), Advances in Consumer Research (Vol. 10, pp. 520-525). Ann Arbor, MI: Association for Consumer Research.

Sternthal, B., \& Craig, C. S. (1973). Humor in Advertising. Journal of Marketing, 37, 12-18. https://doi.org/10.1177/002224297303700403

Stout, P. A., \& Leckenby, J. D. (1986). Measuring Emotional Response to Advertising. Journal of Advertising, 15, 35-42. https://doi.org/10.1080/00913367.1986.10673036

Warren, C., Carter, E. P., \& McGraw, A. P. (2019). Being Funny Is Not Enough: The Influence of Perceived Humor and Negative Emotional Reactions on Brand Attitudes. International Journal of Advertising, 38, 1-21. https://doi.org/10.2139/ssrn.3392607

Weinberger, M. G., \& Gulas, C. S. (1992). The Impact of Humor in Advertising: A Review. Journal of Advertising, 21, 35-59. https://doi.org/10.1080/00913367.1992.10673384

Wirtz, J. G., Sparks, J. V., \& Zimbres, T. M. (2018). The Effect of Exposure to Sexual Appeals in Advertisements on Memory, Attitude, and Purchase Intention: A Meta-Analytic Review. International Journal of Advertising, 37, 168-198.

https://doi.org/10.1080/02650487.2017.1334996

Wong, H. Y. A., McClelland, A., \& Furnham, A. (2019). Advertisement-Programme Congruence in Memory of Sexual Fragrance Advertisements. Applied Cognitive Psychology, 33, 806-813. https://doi.org/10.1002/acp.3523

Zillmann, D. (2000). Mood Management in the Context of Selective Exposure. International Communication Association, 23, 103-123.

https://doi.org/10.1080/23808985.2000.11678971 